\title{
JOAN FUSTER Y LA POESÍA ÁRABE
}

\author{
Por \\ MARÍA JESÚS RUBIERA MATA \\ Universidad de Alicante
}

Estas páginas quieren ser un pequeño homenaje a Joan Fuster, el escritor y pensador valenciano más importante de nuestro siglo, muy recientemente fallecido (Sueca, 1922-1992).

Joan Fuster, ideólogo de lo que podríamos llamar «catalanismo»valenciano, consideró ajena a la cultura de su país la herencia arabigomusulmana. Así lo expresa en su libro más emblemático sobre la esencia de los valencianos, Nosaltres els valencianas que ha merecido cerca de una docena de reediciones y una traducción al castellano:

\footnotetext{
Les primeres tongades de repobladors cristians van assentarse, sobretot, a les ciutats $\mathrm{i}$ en algunes comarques -com les més septreptionals- que havien estar desertades pels sarraïns. A la resta del país continuava predominant l'element musulmà. Santiago Sobrequés ha pogut escriure, i no sense raó, que fins al final del Quatre-cents, els cristians no representaven, en l'àmbit valencià, més que una estructura urbana dirigent. Però aquesta «superestructura» és la que determinarà, en eixemplarse, el tremp nacional dels valencians. Els moros van mantenir-se'n a un costat. Hi quedaven desplegats, en principi, per llur situació de classe servil: tambié, en última instància, per llur retracció irreductible. Van preservarse la llengua -l'algaravia- el credo, les lleis, els vestits, contra qualsevol mira absorcionista dels cristians. Quan, en 1609, eren desterrats per ordre de Felip III, els altres valencians -els valencians per antonomàsia- no van sentir llur absència com una amputació del propi cos social. «Hago gracias a Dios que en Valencia ya no se siente hablar en lengua arábiga» tal és el comentari que algú hi feia. O només ho lamentaren pel dramàtic daltabaix econòmic que va seguir-se'n. Els moros -els moriscos- eren l'autèntica prolongació que, a partir del XIII, tingué vida ailllada i que fou abolida bruscament.

Els valencians, de fet, eren els altres: els «no-moros». I amb ells s'articula la nostra història, la nostra societat, el poble que som en la mesura en què ho som (1).
}

(1) Joan Fuster: Nosaltres els valencians, Barcelona, 1984, 8. ${ }^{a}$ edición, pp. 28-29. 
Esta posición de Joan Fuster fue debida, sin duda, a otra actitud aún más radical de cierto nacionalismo valenciano que creía en el «valenciano» eterno y que gritaba «Antes moros que catalanes», frase que, en contra de lo que podría pensar algún ingenuo, no es precisamente pro-árabe. Porque un hombre con la inmensa cultura de lector impenitente que era Joan Fuster, no ignoraba sin duda que la convivencia entre dos etnias (los valencianos no moros y los moros que convivieron desde el siglo XIII al XVII) implica mutuas influencias que se perciben en la propia literatura valenciana medieval como en Jaume Roig o en Joan Martorell (2) o en los abundantes arabismos del valenciano, especialmente en la agricultura que nos permiten afirmar que si ya no se escucha árabe en las calles de Valencia desde el siglo XVII, el paisaje valenciano sigue hablando con palabras de algarabía.

Posiblemente la aceptación de la herencia árabe como uno de los elementos estructuradores de la esencia valenciana hubiese sido posible desde el punto de vista cultural al modo como lo ha hecho el nacionalismo andaluz (3), cuando la Andalucía occidental o bética tiene posiblemente menos razones para asumir esta herencia que el País Valenciano, pues conquistada por Castilla en el siglo XIII, su población mudéjar fue expulsada por Alfonso X, sin que se escuchase árabe por sus tierras desde entonces al contrario que en el País Valenciano.

El rechazo del pasado árabe como elemento estructurador del valencianismo, fue una opción que Joan Fuster asumió, pero que no significó un rechazo a la cultura árabe y especialmente a su literatura. Lector como ya hemos dicho empedernecido y crítico líterario (4), leyó un día el libro más clásico de las traducciones de poesía hispano-árabe, Poemas arabigoandaluces, de Emilio García Gómez. Suponemos que leyó este libro porque las fechas lo permiten -los Poemas arabigoandaluces desde la primera en 1930 ha tenido numerosas ediciones- y el fragmento traducido al catalán por Joan Fuster procede de la traducción de Ibn Jafāŷa de Emilio García Gómez. Este delicioso librito, Poemas arabigoandaluces, ha sido fuente de inspiración a muchos poetas contemporáneos, por lo que aún está pendiente un estudio sistemático sobre su influencia.

A pesar de su ambigüo título de «poemas arabigoandaluces» la antología de García Gómez no trata de poetas sólo nacidos en tierras de Andalucía, pues andaluz tiene aquí el significado de andalusí y los poetas fueron, los nacidos en diversos puntos de la Península Ibérica, en al-Andalus, incluida, desde luego, Andalucía. Y he aquí que Joan Fuster, opuesto a la idea del valenciano eterno, se sintió impresionado no por cualquier poeta, sino por lbn Jafâya de Alcira, un autor arábigovalenciano.

En la elección Joan Fuster muestra su extraordinario olfato de crítico literario. Ibn Jafấa de Alzira (1058-1139) es, tal vez uno de los mejores si no el

(2) Véase sobre este úitimo, María Jesús Rubiera Mata, Tirant contra el Islam, Alicante, 1993.

(3) Véase, por ejemplo, la obra de Blas Infante, Motamid, último Rey de Sevilla, Sevilla, 1983.

(4) Jaume Pérez Muntaner, Vicent Salvador, Lola Badia y Enric Balaguer Pascual «Joan Fuster. Sobre literatura». Dossier Revista Canelobre, otoño, 1991, n.22, pp. 61-99. 
mejor de los poetas al-Andalus (5), especializado en la descripción de una naturaleza humanizada en la que el rostro humano se dibuja en el paisaje como en una superposición casi cinematográfica. Pero cabe preguntarse si la belleza de los versos de Ibn Jafâya por sí solos es lo que llevó a Joan Fuster a elegirlos como inspiración de los suyos propios o fue el hecho de que Ibn Jafâya hubiese nacido en Alcira y hablase de un río que es el Júcar, el río que también atraviesa las tierras de Sueca, el río del paisaje de siempre de Joan Fuster.

La pregunta es retórica: el poema forma parte de las composiciones de Joan Fuster en homenaje de los autores medievales valencianos como Ausías March.

El poema de Ibn Jafāŷa que motiva el poema de Joan Fuster es el fragmento traducido así por Emilio García Gómez (6):

\section{El Jardín}

El río es dulce, como es dulce la saliva aromática de los labios del amante. El céfiro, que arrastra su húmeda cola, es perezoso.

Ráfagas de perfume atraviesan el jardín cubierto de rocío, cuyos costados son el circo donde corre el viento...

Yo enamoro este jardín donde la margarita es la sonrisa, la murta los bulces, y la violeta el lunar.

Y Joan Fuster publica en su poemario, Terra en la boca, de 1953 (7).

Homenatge a lbn Hafadja d'Alzira

«El riu és dolç, com dolça es la saliva aromática dels llavis de l'amant».

A Rafael Ferreres

El riu és dolç:

de nit, de nit d'agost, demorant-se,

decidit entre flautes tibans i cabelleres,

interrompent les roses, paral.lel a la vida,

el riu pur, oh poeta, serenament t'enyora.

profundament t'enyora, i te busca, i en la prima

àrea del silenci, en les platges que hi traça,

imagina ta veu com una garba estesa,

com un pas o recer d'adolescents exactes,

i t'espera, i espera que tornen, fabulosos,

aquells instants extrets per tu del seu curs plàcid, confegits amb les coses que tu hi sabies veure

-els instants del corser, la seda i la magrana-

oh poeta llunyà, estrany, indesxifrable,

que has decorat ma terra i l'amor amb escenes

(5) M.J. Rubiera Mata, Literatura hispano-árabe, Madrid, 1992, pp. 66, 100, 101, 103-105, 119, 123, 142, 254.

(6) Poemas Arabigoandaluces, Madrid, 1959, 4 edición.

(7) Reeditado en Set libres de versos, edit. 3 i 4, València, 1987, pp. 113-114. Agradezco a Enric Balaguer Pascual su amabilidad al haberme facilitado estos datos. 
de plantes sumptuoses i gaseles fal.laces, poeta tatuat, com el vi, en l'alegria

i t'esperem també, nosaltres, a la vora del riu que comparaves a la dolça saliva, sota la nit coberta de totes les absències, amb la mirada plena del record dels teus versos,

i t'enyoren, i l'altre sense sospirs s'esgarra, i en tos jardins passats brilla la melangia i un poderós punyal de voluntat i espigol representa l'amant o l'estel que comença,

i s'esllangueixen plomes i esclaten caragoles,

i l'urna de la son recull noves tendreses,

i un ocell lateral s'apropia dels arbres,

i la nit cou, i avanga, contigua a la delícia,

fins que ja derivant d'un pensament inerme la lluna, restaurada, exposa la nostàlgia, la lluna violenta, adulta presa grisa cancel.la les cançons, domina desconsola, i tu, poeta antic, designat per un liri, continues ocult, sota el riu, rere el somni

Joan Fuster intenta el distanciamiento - poeta llunyà, estrany, indexifrable que ha decorat ma terra- por la vía del exotismo - plantes sumptuoses i gacel.les fal.laces- para no sentirse afín al poeta árabe de Alzira, ya que el poema le ha sido traducido más allá de la lengua por García Gómez, su tierra fue la misma que la de Joan Fuster, las plantas suntuosas son la margarita, la murta y la violeta y la gacelas están ausentes. Este distanciamiento es de signo opuesto a la aproximación asumida por los poetas andaluces. Recordemos a Manuel Machado en Adelfos (1898-1909) (8).

Yo soy como las gentes que a mi tierra vinieron

-soy de la raza mora, vieja amiga del sol-, que todo lo ganaron y todo lo perdieron

Tengo el alma de nardo del árabe español.

El ejemplo está traído a propósito porque en el poema de Joan Fuster se deslizan algunos elementos del modernismo. Pero estas notas modernistas del poema no provienen del movimiento literario de la confluencia de los siglos XIX y XX sino del modelo árabe, de Ibn Jafâya, pues los poetas de la Edad Media musulmana, fueron modernistas muy avant la leztre. Pues, con todo, Joan Fuster ha sido reducido por el poeta árabe de su tierra a través de la belleza de sus versos. A pesar de sí mismo, cayó en la morofilia valenciana que no se da por el camino de la ética sino de la estética.

(8) Manuel y Antonio Machado, Obras completas, Ed. Heliodoro Carpintero, Madrid, 1973 (r) p. 13. 